\title{
Paediatric Virology: A rapidly increasing educational challenge (Review)
}

\author{
IOANNIS N. MAMMAS ${ }^{1}$, MARIA THEODORIDOU ${ }^{2}$, ANNA KRAMVIS ${ }^{3}$, \\ PRAKASH THIAGARAJAN ${ }^{4}$, SHARRYN GARDNER $^{5}$, GEORGIA PAPAIOANNOU ${ }^{6}$, \\ ANGELIKI MELIDOU $^{7}$, MARIA KOUTSAKI $^{8}$, GEORGIA KOSTAGIANNI ${ }^{9}$, VASSILIS ACHTSIDIS $^{10}$, \\ CHRYSSIE KOUTSAFTIKI ${ }^{11}$, MARCOS CALACHANIS ${ }^{12}$, APOSTOLOS ZARAVINOS ${ }^{13}$, \\ ANNE GREENOUGH $^{14}$ and DEMETRIOS A. SPANDIDOS ${ }^{1}$
}

\begin{abstract}
${ }^{1}$ Department of Clinical Virology, School of Medicine, University of Crete, Heraklion 71003; ${ }^{2}$ st Department of Paediatrics, 'Aghia Sophia' Children's Hospital, University of Athens School of Medicine, Athens 11527, Greece; ${ }^{3}$ Hepatitis Virus

Diversity Research Unit, School of Clinical Medicine, Faculty of Health Sciences, University of the Witwatersrand, Johannesburg 2193, South Africa; ${ }^{4}$ Neonatal Unit, Division for Women's and Children's Health, Noble's Hospital, Douglas, Isle of Man IM4 4RJ, British Isles; ${ }^{5}$ Department of Children's Accident and Emergency, Southport and Ormskirk Hospital NHS Trust, Ormskirk L39 2AZ, UK; ${ }^{6}$ Department of Paediatric Radiology, 'Mitera' Children's Hospital, Athens 15123;

${ }^{7}$ 2nd Laboratory of Microbiology, School of Medicine, Aristotle University of Thessaloniki, Thessaloniki 54124;

${ }^{8}$ Paediatric Neurology Division, 3rd Department of Paediatrics, School of Medicine, University of Athens,

'Attikon' University Hospital, Athens 12462; ${ }^{9}$ Department of Otorhinolaryngology - Head and Neck Surgery, 'Triassio' General Hospital, Elefsina 19200, Greece; ${ }^{10}$ Department of Ophthalmology, Royal Cornwall Hospitals, Truro, Cornwall TR1 3LQ, UK; ${ }^{11}$ Paediatric Intensive Care Unit (PICU); ${ }^{12}$ Department of Paediatric Cardiology,

'Penteli' Children's Hospital, Penteli 15236, Greece; ${ }^{13}$ Department of Life Sciences, School of Sciences, European University Cyprus, Nicosia 1516, Cyprus; ${ }^{14}$ Division of Asthma, Allergy and Lung Biology, King's College London, London SE5 9RS, UK
\end{abstract}

Received November 2, 2016; Accepted December 16, 2016

DOI: $10.3892 / \mathrm{etm} .2016 .3997$

\begin{abstract}
The '2nd Workshop on Paediatric Virology', which took place on Saturday the 8th of October 2016 in Athens, Greece, provided an overview on recent views and advances on Paediatric Virology. Emphasis was given to HIV-1 management in Greece, a country under continuous financial crisis, hepatitis B vaccination in Africa, treatment options for hepatitis C virus in childhood, Zika virus in pregnancy and infancy, the burden of influenza on childhood, hand-foot-mouth disease and myocarditis associated with Coxsackie viruses. Other general topics covered included a critical evaluation of Paediatric Accident and Emergency viral infections, multimodality imaging of viral infections in children, surgical approaches of
\end{abstract}

Correspondence to: Professor Demetrios A. Spandidos, Department of Clinical Virology, School of Medicine, University of Crete, Heraklion 71003, Greece

E-mail: spandidos@spandidos.gr

Key words: Paediatric Virology, viral infections, HIV-1, AIDS, hepatitis B, hepatitis C, Zika virus, influenza, Coxsackie viruses, HPV, MRI, ENT, conjunctivitis otolaryngologists to complex viral infections, new advances in the diagnosis and treatment of viral conjunctivitis and novel molecular diagnostic methods for HPV in childhood. A brief historical overview of the anti-vaccination movement was also provided, as well as presentations on the educational challenge of Paediatric Virology as a new subspecialty of Paediatrics. This review highlights selected lectures and discussions of the workshop.

\section{Contents}

1. Introduction

2. 2nd Workshop on Paediatric Virology

3. Update on current views and advances on Paediatric Virology

\section{Introduction}

Paediatric Virology, which combines Paediatrics with Clinical Virology, is a bold, new and rapidly increasing educational challenge (1-4). Over the past two decades, the new advances in the field of Clinical Virology, as well as in Molecular Medicine, Epidemiology, Evidence-based Medicine, Clinical Governance, 
Quality Improvement, Pharmacology and Immunology have expanded the knowledge base in viral infections occurring in neonates and children (2). Moreover, new vaccines and antiviral agents are currently under investigation and their introduction into clinical practice will contribute towards solving important public health issues in both developed and developing countries. New emerging diseases, such as Zika virus (ZV), West Nile virus (WNV) and Ebola virus (EV) infections, require new prevention strategies and therapeutic protocols, while old viral infections, such as poliomyelitis and hepatitis, are reappearing in areas where these had been thought to be eradicated.

In addition, Paediatric Infectious Diseases (PID) professionals are often involved in the specialised care and follow-up of children with a history of complicated viral infections, such as viral meningitis, surviving to adolescent years and beyond, children with acquired immunodeficiency syndrome (AIDS) and Oncology, Neonatal Intensive Care Unit (NICU), Paediatric Accident and Emergency (A\&E) and Paediatric Intensive Care Unit (PICU) patients, requiring enhanced medical care and innovative technological services. Moreover, recently newfound social issues have arisen including the anti-vaccination wave, the financial crisis and the unprecedented human migrations occurring globally and in the Mediterranean countries in particular (2). These developments and changes definitely highlight the demand for continuing education of paediatricians and PID health professionals in the ongoing advances in the discipline of Paediatric Virology.

\section{2nd Workshop on Paediatric Virology}

This is the second year that the workshop on Paediatric Virology, entitled '2nd Workshop on Paediatric Virology-Paediatric Virology: A rapidly increasing educational challenge', was held. It was hosted at the '21st World Congress on Advances in Oncology' and the '19th International Symposium on Molecular Medicine', which were attended by more than 500 participants from five continents (5). The workshop aimed to bring together virologists with paediatricians and PID health professionals encouraging them to work together as an international network to achieve our goal of promoting children's health against the viral infectious diseases. Its educational programme tried to deliver a wealth of new material covering a diversity of viral infections occurring in infancy and childhood.

It was co-chaired by Professor Maria Theodoridou, Emeritus Professor of Paediatrics at the 'Aghia Sophia' Children's Hospital in Athens, Vice President of the National Immunisation Committee and former President of the Hellenic Paediatric Infectious Diseases Society (Greece), Professor Anna Kramvis, Research Professor of Molecular Virology and Director of the Hepatitis Virus Diversity Research Unit of the University of the Witwatersrand in Johannesburg (South Africa), Dr Sharryn Gardner, Paediatric A\&E/Paediatric Consultant at Southport and Ormskirk NHS Hospital in Merseyside (UK) and Dr Georgia Papaioannou, Head and Consultant Paediatric Radiologist at the 'Mitera' Children's Hospital in Athens (Greece). The workshop was enthusiastically supported by the Department of Clinical Virology of the University of Crete School of Medicine (Greece), the 1st Department of Paediatrics at the University of Athens School of Medicine (Greece) and the Paediatric Virology Study
Group (PVSG). In this review, we present an update on selected topics presented, discussed and evaluated at the workshop.

\section{Update on current views and advances on Paediatric Virology}

The Greek experience of HIV-1 infection in children. The emergence of human immunodeficiency virus 1 (HIV-1) infection in children in 1982 was a new problem of unknown dimensions in all countries, worldwide (6). In childhood, the majority of HIV-1 infections causing AIDS are acquired through mother-to-child transmission (MTCT) of HIV-1 during pregnancy, delivery or breast feeding. In Greece, the diagnoses of the first cases of AIDS were in multitransfused children and adolescents with thalassaemia and haemophilia (Fig. 1). They were infected prior to 1985, when HIV-1 screening and inactivation of blood products was initiated. The prevalence rate of HIV-1 infection ranged from 2 to $11 \%(6-8)$. The size of the problem in vertically infected children was unknown; however, the incidence of infection among women was found to be low, 1:10,000. Moreover, the number of infected babies was small and remains so with the implementation of the preventive strategy with zidovudine and antiretroviral treatment during pregnancy and the neonatal period (9). Effective prevention has reduced the risk of the perinatal transmission of HIV-1 to $<1-2 \%$.

In Greece, the 'new' infectious disease necessitated the establishment of a special Paediatric AIDS Unit at the 'Aghia Sophia' Children's Hospital, in Athens, which became the national reference centre (6). The Unit had a multifaceted goal. The main activity was both the treatment and the social-psychological support of the children, their parents and relatives. Efforts were also made to collaborate with the AIDS Units for adults and the Maternity Clinics to ensure the prompt management of the HIV-1-positive pregnant woman and her newborn. All babies had a follow-up period of 2 years $(10,11)$. The educational role of the Unit for healthcare personnel, students and the public, during a period of unreliable fears and prejudices, was also of great importance. In a rather short period of time, as a result of the scientific achievements in all fields, the prognosis of HIV-1 infection has changed. HIV-1 has been transformed from a progressive and often fatal infection to a chronic condition (12). Unfortunately, children and adolescents of the initial AIDS period did not have the privilege of the anti-retroviral therapy. There are still a lot of challenges involved in the treatment of this infection and its long term adverse effects (13). There is also an urgent need for the development of child-friendly medication. Moreover, HIV-1-infected children survive to adulthood and there are many new issues regarding their transition to adult care. Intensive education and support is important for the adherence to drug regimens, which will enable them to lead a good quality of life (14). The vision of no new HIV-1 cases can be achieved with effective prevention strategies for the perinatal transmission, but also with prevention of HIV-1 infection in youth (15).

Hepatitis $B$ vaccination in Africa. Worldwide, there are 240 million chronic carriers of hepatitis B virus (HBV), of which at least 65 million reside in Africa (16-18). In sub-Saharan Africa, HBV is hyperendemic and there is a corresponding high incidence of hepatocellular carcinoma (19). 


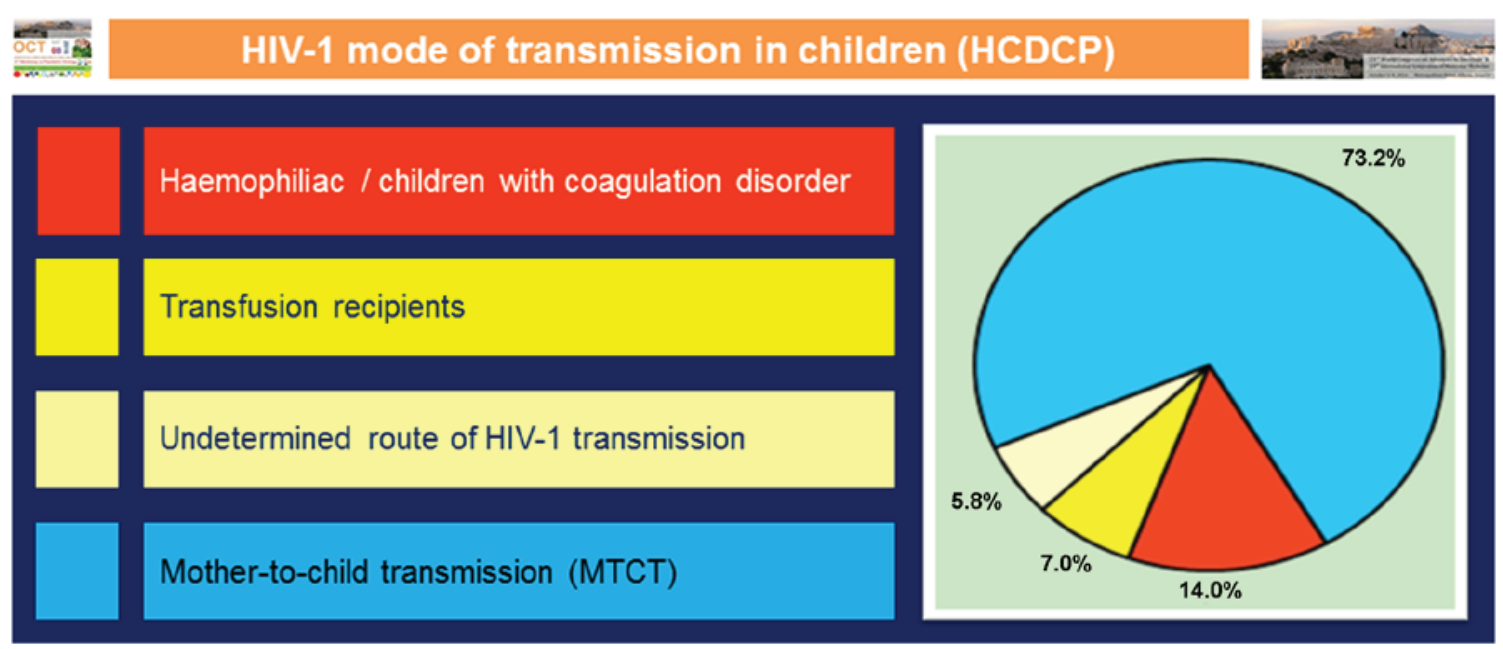

Figure 1. Paediatric cases of HIV-1 infection by transmission group reported in Greece by 31/12/2014 - adapted from Hellenic Centre for Disease Control and Prevention (HCDCP) (11).

In September 2015, the '1st World Hepatitis Summit', held in Glasgow, Scotland (UK), resolved that a concerted effort should be taken to eradicate HBV infection globally by the year 2030 (20). If we desire to eradicate HBV globally by the year 2030, that leaves us with a period of 15 years, HBV research in Africa has to be given the attention it deserves. For far too long, HBV has been eclipsed by the 'blockbuster' infections that cause AIDS, malaria and tuberculosis, even though the global burden of HBV is equivalent to that of malaria and tuberculosis.

The most effective method for preventing HBV infection is vaccination. The hepatitis $B$ vaccine is the first vaccine to act against two viruses, HBV and hepatitis D virus (HDV), against chronic and sexually transmitted disease and against cancer. The risk of chronic HBV infection is inversely proportional to the age at which HBV infection is acquired. Therefore, it is important to prevent HBV infection as early as possible. Although the World Health Organization (WHO) recommends birth dose vaccination (21), this is not implemented in most African countries. Both monovalent and multivalent $\mathrm{HBV}$ vaccines are administered, usually with a 6-10-14-week schedule (22). Although the coverage of the 3rd dose of the HBV vaccine has 'caught up' with the world average of $82 \%$, it still has not reached that of other regions of the world, apart from Asia (23). There are regions in Africa, such as South Sudan, for which no data are available, as well as regions, where there is $<50 \%$ coverage, such as Chad, Central African Republic (CAR) and Somalia (23). The coverage in the northern countries has decreased, as a consequence of the events of the 'Arab Spring'. Conflicts and violence in Mali, Sudan, South Sudan, Cameroon, Nigeria, Chad and CAR have caused the displacement of large sections of the population and have added to the economic causes of migration from Africa, mainly to Europe. Thus, HBV is being carried from areas of high endemicity to areas of low endemicity, and the introduction of HBV to these regions, where universal vaccination is not generally practiced, will definitely hamper efforts for the global eradication of HBV.
Treatment options for hepatitis $C$ virus in childhood. Hepatitis $\mathrm{C}$ virus (HCV) infection is a major global health concern (24). According to WHO, globally at least 170 million people are infected with $\mathrm{HCV}$, accounting for $3 \%$ of the world's population $(24,25)$. There is a paucity of data on its prevalence in children, mainly due to the lack of screening and the asymptomatic course of infection in children (26). The prevalence in children ranges from $0.05 \%$ in developed countries to $9 \%$ in rural areas of Egypt, which also has the highest adult prevalence worldwide (27). The most common HCV strain circulating in children in genotype 1 (26). HCV can be transmitted iatrogenically to children, by blood transfusions, transplantations and unsafe injection practices (26). However, MTCT remains a major route of infection and infected neonates become chronic carriers of HCV. The major risk factor for MTCT is high viral loads and elective caesarian section is recommended when viral loads exceed $105 \mathrm{IU} / \mathrm{ml}$, as currently there are no effective methods to prevent MTCT (28). There are no recommendations for the use of drugs for the prevention of perinatal infection (26). HCV infection is generally asymptomatic in childhood, with mildly abnormal transaminases and hepatic damage is minimal. However, fibrosis is correlated with age and duration of infection, thus children should be monitored and treated, as early as possible, to avoid disease progression.

Although the standard of care treatment regimens of pegylated interferon (IFN) combined with ribavirin are well tolerated and effective in children (28-31), they are lengthy, relatively toxic and expensive (Fig. 2). Fifty percent of patients infected with genotype 1 will not respond to this treatment (30). Genotypes 2, 3 and 4 yield the optimal sustained virologic response (SVR) of $>80 \%$ (30). In February 2016, WHO updated its HCV treatment guidelines (32). It was recommended that direct-acting antiviral (DAA) regimens should be used for the treatment of persons with HCV infection rather than regimens with pegylated IFN/ribavirin. DAA regimens target the $\mathrm{HCV}$ protease, polymerase and NS5A, the protein necessary for viral replication and assembly. Although animal reproduction studies have failed to demonstrate a risk 


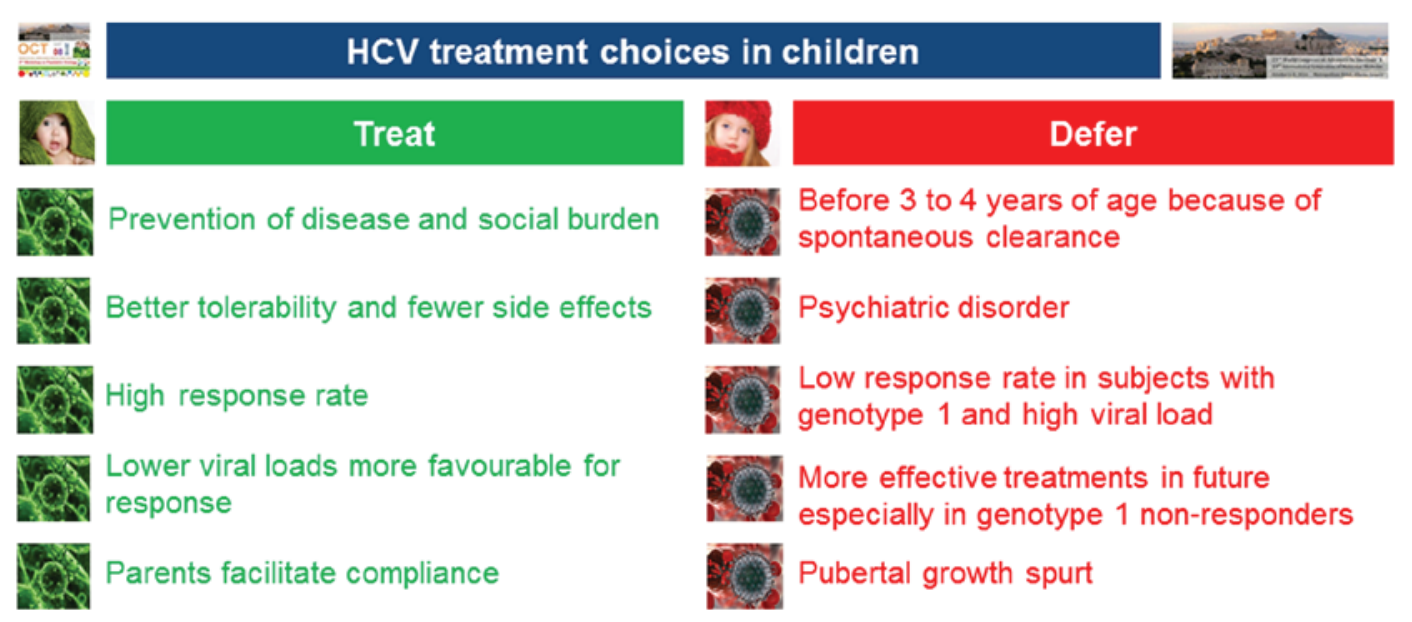

Figure 2. HCV treatment choices in children: To treat or not to treat children for HCV? - adapted from Wirth et al (30).

of using currently available IFN-free treatment modalities for HCV to the foetus (24), to the best of our knowledge, there are no adequate and well-controlled studies on pregnant women currently available. Moreover, DAA regimens have not been licensed for use in children as their safety in children has not been determined. It is hoped that a positive outcome in pending clinical trials in children for IFN-free DAA regimens will revolutionise therapy for $\mathrm{HCV}$-infected children as they have for their adult counterparts (33). Moreover, if widely used, these DAA regimens may also contribute to eliminating MTCT.

$\mathrm{ZV}$ in pregnancy and in infancy. $\mathrm{ZV}$ is a single-stranded RNA virus, closely related to dengue fever, yellow fever, Japanese encephalitis and WNV infections $(34,35)$. Zika is the name of the disease caused by this virus. The primary mode of transmission is via the bite of infected Aedes aegypti and Aedes albopictus mosquitoes (36). Other modes of infection include maternal/foetal transmission (intrauterine and perinatal), sexual transmission and laboratory exposure (37). Outbreaks have occurred in 48 countries and territories (38). All age groups are affected, although adults are more likely to seek medical attention. The clinical illness is usually mild, the incubation period varies from 3 to 14 days and viraemia occurs for up to a week (39). The majority of the infections are subclinical and the most common clinical features include an acute onset of fever, maculopapular rash, arthralgia and conjunctivitis, although headaches and myalgia have also been reported (40). $\mathrm{ZV}$ disease during pregnancy is of particularly concern as foetal and perinatal transmission have been reported, causing microcephaly and other severe defects, including eye defects, hearing loss, impaired growth and foetal loss (36). Definitive diagnosis is based on the detection of $\mathrm{ZV}$ ribonucleic acid (RNA) in blood - serum or ideally, ethylenediaminetetraacetic acid (EDTA)-treated plasma - and other body fluids by polymerase chain reaction (PCR) (6). The most recent updated interim guidelines for the evaluation and management of infants with possible congenital ZV were published by the Centers for Disease Control and Prevention (CDC) in August 2016 (41).

Paediatric A\&E: viral infections on the frontline. Viral infections are very common in infancy and childhood with estimates of between 8 and 18 infections per child per year $(42,43)$. While these may sound benign or trivial, often children will be unwell for several days, and this thus affects on parents' professions and certainly sleep, as well as the child's education. Understandably, if there is a treatment available, parents will be willing to make use of it. The result of better and better emergency facilities is parents presenting with their viral infections at an emergency service - general practitioners (GPs), Walk in Centres (WICs), or A\&E. When diagnosed, some bemoan the infection being 'just a virus' for the tenth time as if they had somehow failed in the quest for the 'magic bullet' of antibiotics (44). 'It's just a virus' is a common complaint from families, and publications discuss this (45). Doctors have perhaps failed to express the risks of antibiotics, particularly in those where it is not indicated, and have not adequately challenged the mistaken view that antibiotics cure all infections. Emergency Departments (EDs) may not release children with fever and a clear focus of infection until the temperature drops, subconsciously giving the message that children with fever somehow deserve to be and indeed, should be in an ED. Doctors need to justify not pursuing expensive investigations and treatments of clinically insignificant viral infections. Undoubtedly, doctors could prescribe fewer antibiotics for viral infections, $20 \%$ of which are treated with antibiotics (46). However, only 2/3 of urinary tract infections (UTIs) are treated acutely with antibiotics in a busy Paediatric ED (47). Sepsis guidelines and focus also suggest that doctors could improve their skills at identifying those who need urgent antibiotics and support (48).

The University of Utah (USA) has investigated the increasing amount (percentage) of time families have viruses detected, depending on the number of children in the home, from $18 \%$ in those with no children to $87 \%$ in those with 6 , although only approximately $50 \%$ of these were found to produce symptoms (49). This same principle is captured in the phenomenon of 'nursery syndrome', where children in nurseries seem to constantly have infections, often leading to invasive tests as parents push for another (more sinister or medical) answer. The CDC has helpfully produced guidelines for when to investigate this (50) and a website about periodic fever is entitled itsnotjustavirus.com (51). Parents' views toward viruses are complex and often inconsistent or diametrically opposed. 


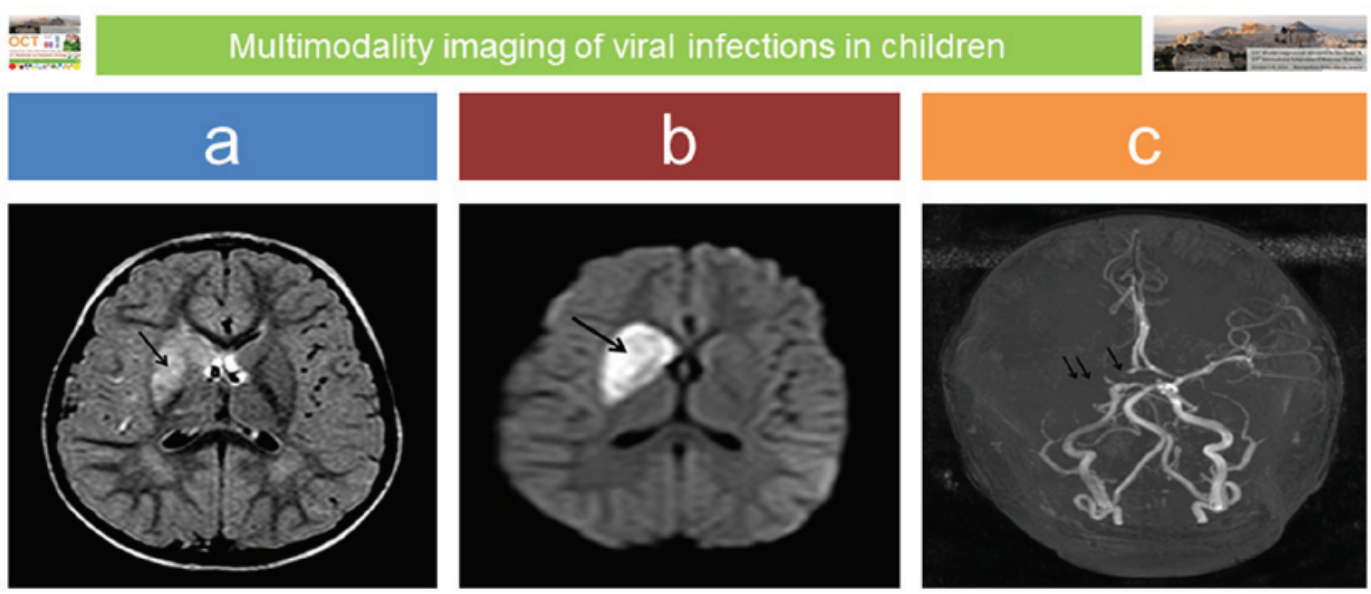

Figure 3. Post-varicella vasculitis and stroke: a 3-year-old boy presented with acute onset of left upper arm weakness and facial nerve palsy; there was a recent previous history of 'gastroenteritis'. MRI performed on emergency admission revealed an extensive area of abnormal signal intensity at the region of the right basal ganglia on axial fluid attenuation inversion recovery (FLAIR) image (arrow in panel a), which presented restricted diffusion on diffusion weighted imaging (DWI) sequence (arrow in panel b) in keeping with acute ischaemic infarct. Absence of flow void on magnetic resonance angiography (MRA) was confirmed in the proximal part of the right anterior cerebral artery (ACA) (single arrow in c) and along the right middle cerebral artery (MCA) (double arrow in panel c).

The unnamed 'just a virus' is trivial, while life-threatening viruses are deemphasized in parents' desire to protect their child from perceived risks of mass vaccination programmes. Any new virus is a potential pandemic with the capacity to annihilate the world, forgetting that we have few viral treatments even for those that have been around for centuries. Names of these new viruses in the mass media increase this anxiety - ZV, EV, Nipah virus (NiV) and Hendra virus (HeV), for example. The perception of multiple treatments for viruses, such as HIV-1, may fuel this - perhaps if we carried out further research, we would be able to treat all viruses. Conservative supportive management is seen as condescending or inadequate, while many parents do not adequately encourage fluids intake or administer antipyretics regularly enough. In the future, there is much work to be done in both medical and public perceptions of viral illnesses.

Multimodality imaging of viral infections in children. Foetuses, infants and children are susceptible to a wide variety of viral infections, most commonly involving the central nervous system (CNS) and the chest, in greater frequency than adults (52). Advances in imaging modalities have enabled the detailed exploration of pathologies, symptoms and signs in children starting from foetal life. Although imaging is practically unable to confirm the diagnosis of viral infection or identify the pathogen, it has the potential to accurately suggest the presence of a viral infection and to direct further investigations accordingly. Additionally, it may reveal complications of viral infections that may cause diagnostic uncertainty and usually require special treatment.

Specific imaging findings are highly suggestive for CNS viral infections in foetuses, infants and children, particularly if these infections are subdivided into the following categories: congenital in neonates, aseptic meningitis/encephalitis, acute disseminated encephalomyelitis (ADEM) in older children and HIV-1 infection (53). Familiarity with the clinical course, the route of transmission and imaging appearances usually proves helpful in reaching the correct diagnosis and in prompting timely treatment. In general, the sequelae of an intrauterine infection reflect a combination of the pathogens and the stage of foetal development at which the exposure occurred (54). Congenital infections occurring during the second and third trimester may persist in the neonate, affecting its general and neurologic status (54). However, as a rule of thumb, the later the diagnosis of congenital infections is made, the more difficult it is to identify the agent and the imaging findings may become non-specific and less conspicuous, as incomplete white matter myelination may interfere with the pathology (54). In neonatal brain infections, magnetic resonance imaging (MRI) is the modality of choice even in an emergency setting (55). It accurately demonstrates focal lesions, usually associated with deep venous infarcts, diffuse white matter oedema and/or findings of meningitis. With some agents, such as reactivated latent herpes simplex virus 1 (HSV-1) in older children, imaging is so specific that it may be diagnostic: foci of haemorrhage and dystrophic calcification acquiring a gyriform pattern are observed both on computed tomography (CT) and MRI with a predilection for the temporal lobes (54). Additionally, recent studies support that in children with other causes of viral encephalitis, neuroimaging features may suggest the pathogens (55). In the presence of arterial ischaemic stroke in children, post-varicella infection vasculitis should be considered (56) (Fig. 3).

ADEM is a monophasic, immune mediated, inflammatory and demyelinating disease of the CNS with multifocal white matter lesions on imaging and diffuse neurological signs, usually presenting a short time after viral infection or vaccination, though in some children no associated trigger can be identified $(57,58)$. The identification of typical imaging findings - multiple, asymmetrical areas of abnormal signal intensity in the white matter without contrast enhancement that resolve on follow-up MRI - or atypical imaging patterns suggestive of ADEM may enable prompt treatment, thereby avoiding confusion and prevent development of severe sequelae, improving the outcome.

The predominant radiological pattern in viral pneumonia in childhood is patchy areas of confluent air-space shad- 


\section{HCDCP annual report on epidemiological surveillance of influenza}

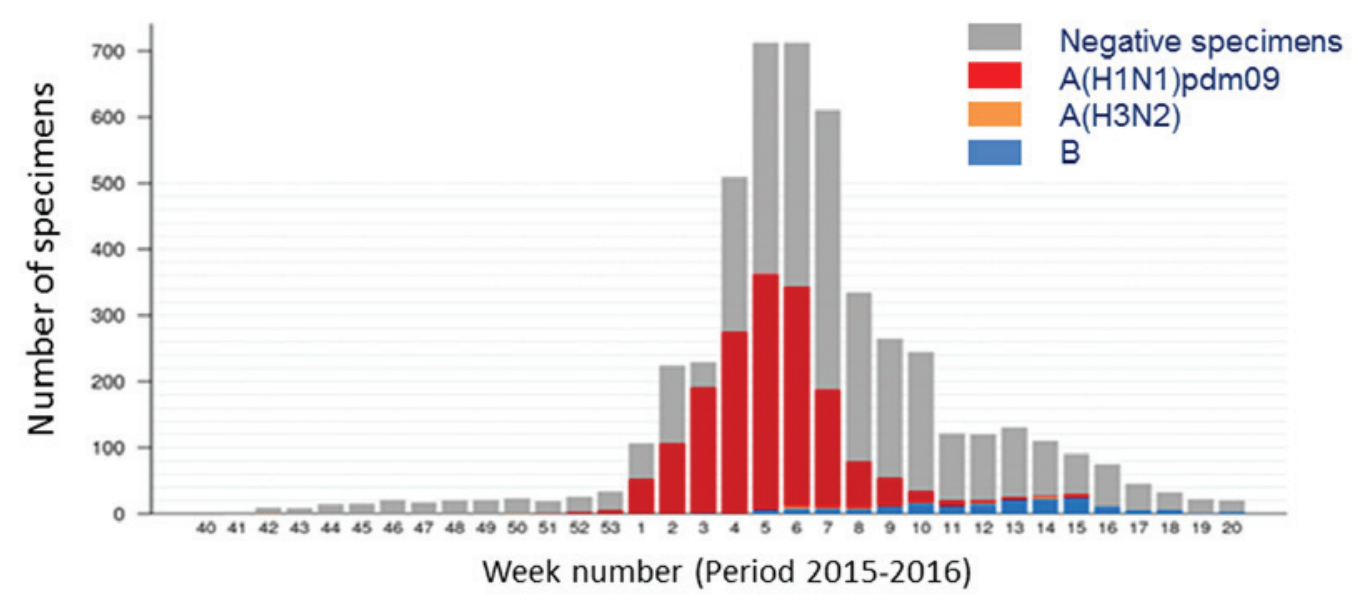

Figure 4. Total number of specimens tested for influenza viruses and positive specimens for each influenza subtype during 2015-2016 in Greece-adapted from Hellenic Centre for Disease Control and Prevention (HCDCP) (71).

owing with bilateral distribution and/or interstitial pattern; however, lobar consolidation-especially in cases caused by the respiratory syncytial virus (RSV)-may be encountered (59). Additionally, interstitial infiltrates are seen both in viral and bacterial pneumonias (60). Radiological information could aid the differential diagnosis, management and response prediction in children with viral pneumonia (59). Laboratory confirmation of the specific causative organism is mandatory.

Viral gastroenteritis is very common in children. It does not often require imaging confirmation unless a complication has developed, i.e., intussusception, acute abdominal pain due to secondary appendicitis (61). In these instances, ultrasonography is the modality of choice to confirm the diagnosis; in the presence of intussusception, usually caused by enlarged mesenteric lymph nodes, radiologic air-reduction provides a minimally invasive treatment. In the presence of Epstein-Barr virus (EBV) infection ultrasonography of the abdomen may reveal coexistent imaging features of acalculous cholecystitis (62).

In the exploration of neck masses in children with viral infection, ultrasonography usually reveals typical appearances of reactively enlarged lymph nodes; in suspicion of EBV infection, ultrasound appearances of the affected lymph nodes may even suggest the pathogen - an heterogenous appearance with prominent lymphoid follicles (63). Post viral acute rhinosinusitis in children usually does not require imaging, unless there is clinical deterioration following initial symptom improvement; bacterial supra-infection is usually the underlying cause and cross-sectional imaging is indicated to rule-out endocranial or orbital extension (64). Synovitis, usually of the hip joint, is a not uncommon sequela of systemic viral infections. It is easily confirmed with hip ultrasound and usually requires no further imaging. However, osteomyelitis, which is a recognised but uncommon complication of viral infections, should be further investigated with MRI. A few reports of chickenpox osteomyelitis reveal formation of subperiosteal abscesses (65).

Influenza in childhood: a usual suspect. The global burden of respiratory illness in childhood is substantial and influenza viruses contribute to a large part of this burden $(66,67)$. The disease burden in terms of high rates of infection, complications and hospitalisations is high, particularly during the early years of life. Influenza A and B virus infections are common reasons for hospitalisation and they are associated with substantial mortality in children. A global systematic analysis that used 1982-2012 surveillance data to provide an estimate of influenza-associated hospitalisations among children worldwide, revealed that there are annually 374,000 hospitalisations in children $<1$ years of age, of which 228,000 are in children $<6$ months of age (68). In total 870,000 hospitalisations are estimated to occur annually in children $<5$ years (68). Influenza-associated hospitalisation rates are more than three times higher in developing countries than in industrialised countries (68). The various seasonal influenza types and subtypes, such as $\mathrm{A}(\mathrm{H} 1 \mathrm{~N} 1)$ pdm09, A(H3N2), B-Yamagata lineage and B-Victoria lineage, are associated with variable disease severity rates, particularly in the presence of underlying medical conditions, such as asthma, diabetes, neurological conditions, chronic lung disease and heart disease. The highest admission rate is found in children $<3$ months of age, while children infected with influenza B are typically older than those infected with influenza A (69). Children between 5 and 59 months of age are generally considered as a high-risk group (70). In some countries, there have been reports of hospitalisations with severe disease associated with influenza A(H1N1)pdm09 infection during 2015-2016, mainly at the young/middle aged adult group (70). In Fig. 4, we present the total number of specimens tested for influenza viruses and positive specimens for each influenza subtype during 2015-2016 in Greece according to the Hellenic Centre for Disease Control and Prevention (HCDCP) (71).

Rapid laboratory diagnostic methods and further genotypic and phenotypic analysis that are performed at the National Influenza Centres can assist in the timely and effective treatment of the infections (71); available antiviral agents can substantially shorten the duration and the severity of the viral illness and prevent the development of bacterial complications when administered within the first 48-72 $\mathrm{h}$ from the onset of 
symptoms. The neuraminidase inhibitors oseltamivir and zanamivir lie at the front line of defense against influenza infections, as influenza viruses are at present widely susceptible to those drugs. Only $0.5 \%$ of globally circulating $2014-2015$ viruses has been identified as resistant to those antiviral drugs (72). Importantly, this percentage has remained relatively stable, compared to influenza season 2012-2013 and 2013-2014 (72).

In parallel, WHO is putting a great effort into the the early annual prediction of circulating stains and the detection of antigenic variants caused by the viral antigenic drift of seasonal influenza viruses, in order to assist in vaccine production. Vaccines against influenza can be administered in one or two doses after 6 months of age and have the potential to prevent infection to a great extent, depending on the circulating variants. The past influenza season vaccine effectiveness was reduced due to the circulation of B-Victoria lineage, instead of B-Yamagata lineage that circulated the previous seasons and was therefore included in the vaccine (73). For this reason, WHO recommended an altered composition of the 2016-2017 vaccine, to include B-Victoria in the trivalent vaccine. Despite the genetic evolution of $\mathrm{A}(\mathrm{H} 1 \mathrm{~N} 1)$ pdm09 viruses, the majority of $6 \mathrm{~B}$ viruses including those in newly emerging sub-subgroups, remain antigenically closely related to the vaccine virus (70). Furthermore, the low vaccine effectiveness of the LAIV vaccine has recently been observed in children in the USA (74), while these findings are not supported by the UK and Finland $(75,76)$. The continuous epidemiological and virological surveillance of influenza viruses is essential in order to monitor and effectively control annual influenza outbreaks.

Neurologicmanifestations of influenza in childhood. Influenza A infection is a common seasonal infection, resulting in a variety of manifestations, ranging from mild illness, such as upper respiratory tract infection and gastroenteritis, to severe complications, such as respiratory distress syndrome, myocarditis and meningoencephalitis (77-79). Neurological complications are well recognised in influenza infection, with different strains demonstrating varying degrees of neurovirulence (80-82). Severe neurological sequelae are more often observed following infection by influenza A pandemic strains (83-85), and in case of the recent pandemic influenza $A(H 1 N 1) p d m 09$ infection represented the most severe consequence of influenza in children second only to death (86). The neurologic sequelae of influenza A infection in children vary greatly. In the most recent influenza outbreaks, the two most common neurologic complications reported were seizures (both febrile and non-febrile) (87) and encephalopathy (88). Other less common complications included neuropsychiatric manifestations, stroke (89), focal neurologic deficits $(88,90)$, Guillain-Barré syndrome (91) and ADEM (88). The link between seizure onset and influenza infection is currently well characterised, yet modestly understood. It is believed that $\mathrm{A}(\mathrm{H} 1 \mathrm{~N} 1) \mathrm{pdm} 09$ infection plays a role in the aetiology of febrile convulsions through a molecular cascade, involving neurotropic cytokines (92), the degree of fever per se, an unrecognised mild viral encephalitis or toxic encephalopathy and a potential reactivation of latent human herpes virus 6 (HHV-6) infection (93).

Approaches of otolaryngologists for complex viral infections. Viral infections of the upper airway tract are quite common in children and infants (94). They can cause various symptoms and they rarely demand surgical intervention. In certain cases though, viral infections can cause lesions that need to be surgically removed or treated. Differential diagnostic difficulties may also lead to surgical intervention by the head and neck surgeon (aspiration for biopsy and endoscopy). The viruses responsible for such lesions are usually human papillomavirus (HPV), RSV and HSV-1.

HPV subtypes 6 and 11 cause papillomas, which can sometimes lead to an obstruction of the airway tract, particularly in infants and can even be fatal (95). Vertical MTCT of HPVs during birth is well recognised. HPVs can be found in the oral cavity, the pharyngeal wall and larynx, while recurrent lesions are common occurrences. Oral squamous papillomas are benign lesions, which can be found as a papillary or verrucous exophytic masses. These lesions are often asymptomatic and have limited progression. Current surgical treatment includes classic endoscopic surgery (cold steel removal), transoral laser microsurgery (TLM) using $\mathrm{CO}_{2}$ laser and microdebriders. Surgical removal by curettage or cautery have good success rates of $65-85 \%$, but scarring and recurrence can occur in up to $30 \%$ of cases. The erbium-doped yttrium aluminium garnet (Er:YAG) laser has a small zone of thermal damage, allowing more precise thermal ablation with less scarring. Neodymium-doped yttrium aluminium garnet (Nd:YAG) laser light can be used through fiberoptics in a flexible probe along with the suction channel to treat recurrent respiratory papillomatosis (RRP) caused by HPV 6 and 11 in children (96). The most commonly used method nowadays for the surgical treatment of such lesions is TLM. This method has several advantages including successful haemostasis, wound sterilisation and is devoid of sutures, while it minimises post-operative pain (97). Official guidelines and recommendations for the treatment of HPV lesions vary with the site and type of wart (98).

Acute laryngotracheitis is also a common clinical condition found in children (94). The aetiology is mostly viruses, such as parainfluenza viruses 1, 2 and 3, RSV, influenza virus, human adenovirus and less commonly HSV-1. This condition may lead to the sudden obstruction of the upper airway tract and may demand the intervention of the otolaryngologist to perform tracheostomy, when intubation is not possible (99). RSV is a common cause of respiratory infections and airway distress in young children. Hospitalisation is required in 1 and $2 \%$ of infected children, while almost $8 \%$ of those children that have been hospitalised will eventually require mechanical ventilation. The otolaryngologist's role is to preserve an open airway tract performing tracheostomy, when necessary (100). In certain cases, a viral infection can lead to the formation of a neck abscess, when bacterial co-infection is also involved. This rare occurrence requires the otolaryngologist's surgical intervention (incision-and-drainage) in order to treat the abscess using a needle or steel. Non-treated abscesses can lead to serious complications such as sepsis, mediastinitis, necrotizing fasciitis and airway obstruction (101). The paediatrician's role is the most important in order to provide the correct diagnosis. Paediatricians and otolaryngologists must cooperate to ensure the patient's safety and successful treatment.

New advances in viral conjunctivitis. Conjunctivitis is the inflammation and erythema of the conjunctiva, secondary to 
infection - viral or bacterial - or allergic reaction (102-104). It may present with burning, stinging, ocular discharge, foreign body sensation and eyelid swelling. Viral aetiology in children may account for up to $50 \%$ of all cases (102-106). Most commonly, viral conjunctivitis is caused by human adenovirus, which may involve upper respiratory infection and gastroenteritis. Epidemic keratoconjuctivitis, a highly contagious infection is due to adenovirus serotypes 18, 19 and 37, is associated with follicles, pre-auricular lymphadenopathy, periorbital pain and diffuse superficial keratitis. Complications include persistent sub-epithelial cornea opacities, conjunctival scar formation and vision glare. Topical steroid drops are then needed to be judiciously administered and treatment may continue for months (102-105). Pharyngoconjuctival fever is another category of conjunctivitis caused by adenovirus serotypes 3 or 7 . It presents with subconjunctival haemorrhage, oedema, lid swelling, watery discharge, sores and fever, follicular conjunctival reaction and preauricular lymphadenopathy. Treatment is supportive and the infection lasts for a couple of weeks, while the cornea is usually not involved in the infection. Herpes conjunctivitis is more commonly unilateral and the typical herpetic eyelid vesicles help to identify the cause. There is conjunctival redness, discomfort and foreign body sensation. Cornea epithelial disease is marked by dendritic ulcers. HSV-1 is the cause of primary eye infection. Treatment involves acyclovir drops 5 times/day or trifluridine $1 \% 6$ drops/day for 2 weeks. The debridement of the infected area of the cornea is also considered. Oral acyclovir has been shown to reduce the recurrences of herpetic epithelial keratitis/iritis if used prophylactically (102-106).

HSV-2 is associated with neonatal eye infections and it is congenital. It may be complicated by dendriform or geographic keratitis. Diagnosis is clinical, but in atypical cases enzyme-linked immunosorbent assay (ELISA) testing can confirm the diagnosis. Varicella-zoster virus (VZV) is a herpes virus causing the characteristic exanthema of chickenpox, mild conjunctivitis, and rarely, keratits and iritis. Ocular involvement is often mild and self-limited; however, topical antibiotic drops may prevent a secondary infection. Reactivation of a latent VZV from dorsal root and cranial nerve ganglia causes the zoster infection and conjunctivitis/keratitis/iritis may occur, most likely if the nasocilliary branch of the V1 nerve is affected $(103,104,107)$. Infectious mononucleosis is caused by EBV with fever, lymphadenopathy and often mild conjunctivitis, which tend to be self-limited. Influenza, mumps and rubeola are other causes of viral conjunctivitis and the diagnosis is clinical. Treatment is supportive with cool compresses on the eyelids and topical antibiotics $(108,109)$. Enterovirus serotype 70 is the most common cause of a highly contagious conjunctivitis, which is usually described as acute haemorrhagic conjunctivitis. Infection often becomes symptomatic within one day, lasts for a week and causes characteristic painful subconjunctival haemmorhages. While the prognosis for the child's vision is usually good, cornea microbial superinfections may occur. Molluscum contagiosum is caused by a deoxyribonucleic acid (DNA) pox virus and presents as ubiligated skin lesions perioculary. Lesions near the eyelid margin may cause chronic follicular conjunctivitis and may require surgical excision (107). Overall, conjunctivitis is very common among children with various aetiologies and similar clinical presentation. The proper use of antibiotics, antiviral or steroid drops is the most effective method to manage infection and increase patient satisfaction.

Onychomadesis and hand-foot-mouth disease (HFMD). Onychomadesis is the complete shedding of the nails from the proximal portion, due to temporary arrest of the function of the nail matrix (110). It is a rare disorder in children and the prolonged insult to the nail matrix may be due to local trauma (e.g., manicure, onychotillomania and ill-fitting footwear), local cutaneous disease (dermatitis, paronychia), drugs (retinoids, chemotherapy agents), pemphigus, Kawasaki disease and viral infections. Recently, it has been recognised as a complication in the course of the common viral infection of HFMD. The association between onychomadesis and HFMD was first reported by Clementz and Mancini (111) in 2000 and by Bernier et al (112) in 2001.

HFMD is a highly contagious viral infection that occurs mainly in summer and early autumn. It presents with a sore throat and mouth pain and is characterised by enanthema, exanthema (macular, maculopapular, or vesicular) that involves the dorsum of the fingers and toes, the interdigital area, palms, soles, upper thighs and arms. It is mainly due to Coxsackie virus (CV) A16 and A71 (113,114). Since 2008, the epidemics in Europe and Asia, and in 2011 in the USA, were attributed to a new genotype, CV A6 $(115,116)$. This genotype is responsible for atypical and more serious manifestations, such as higher fever, wider distribution of the lesions (involvement of the extremities, face, lips, perioral area, buttocks, groin and perineum), more extensive skin involvement (vesiculobullous lesions, bullae, ulcerations, eschar formation) and longer duration (mean duration 12 days) (117,118). Moreover, rare complications have been also described, such as palmar and plantar desquamation one to three weeks after HFMD and nail disorders, beau lines and onychomadesis one to two months following HFMD (119). To date, the exact pathophysiological mechanism of nail shedding has not been elucidated (119). Biopsies of HFMD vesicular lesions reveal loose strands of fibrin, lymphocytes, monocytes and neutrophils within vesicular fluid. Extensive acantholysis with reticular degeneration is detected in the overlying epidermis, along with perivascular foci of lymphocytic, monocytic and neutrophilic leukocytes in the upper dermis (120). Although there are some publications describing onychomadesis related to CV A6 infection, no clear correlation between the virus type and HFMD-related nail changes has been demonstrated $(119,121)$. The diagnosis is made based on the characteristic clinical manifestations and very rarely is there a need for confirmation using PCR detection from throat, stool and vesicular fluid samples. Nucleic acid amplification is preferred to cell culture due to increased sensitivity. There is no specific antiviral therapy for the treatment of enteroviruses and management is mainly supportive. The clinical course of HFMD is mild and complete resolution of symptoms and signs typically occurs within 7-10 days. Severe disease with neurologic or cardiovascular complications (encephalitis, meningitis, flaccid paralysis, myocarditis) is seen after CV A71 infection. It is important that the paediatricians become familiar with the rare complications of the disease, such as onychomadesis, as they may become evident weeks or even months later, and thus do not appear to be related to the original disease. 
Viral myocarditis in children. CVs belong to a family of non-enveloped RNA viruses, Picornaviridae and the genus Enterovirus, which also includes poliovirus and echovirus (122). They are named after the town Coxsackie in New York, where they were discovered. CVs are divided into two major subgroups, labeled A and B. Type A viruses usually cause only enteric diseases, while type B viruses can cause serious diseases beyond the intestinal tract, such as pharyngitis, myalgia, meningitis and myocarditis (122-124). Myocarditis is an inflammation of the myocardium that triggers an immune response, which results in myocardial oedema, necrosis and apoptotic degeneration of the cardiac myocytes with the subsequent impairment of systolic and diastolic function. Clinically, the manifestation of myocarditis is relatively uncommon in infants and children. The subclinical presentation of the disease is much more prevalent (125). Children affected by myocarditis typically present with sinus tachycardia and gallop rhythm on auscultation, cardiomegaly on chest X-ray and small voltages on the electrocardiogram (ECG). The presence of arrhythmia in the context of a febrile illness should point the clinician to the possibility of myocarditis. Paroxysmal atrial tachycardia (126), ventricular ectopy (127-129) and various degrees of heart block (130) have all been described in association with MC. Echocardiography often reveals impaired left ventricular contractility-left ventricular ejection fraction $(\mathrm{LVEF})<50 \%$, and a certain degree of mitral regurgitation due to mitral annulus dilatation or leaflet dysfunction. Pericardial effusion may be also present. Symptoms of myocarditis may include fever and malaise, with the addition of non-specific chest pains that may be due to possible associated pleural or pericardial inflammation. In most cases, the disease is resolved spontaneously without any treatment. However, in approximately $20 \%$ of cases, there can be extensive damage to the the heart, causing arrhythmias, severe left ventricular dysfunction and, in more severe cases, heart failure requiring heart transplantation. Oxygen, diuretics and inotropic agents, such as dopamine or dobutamine, may be needed and the administration of these drugs requires admission to PICU with intravascular blood pressure monitoring. Digitalis should be used with extreme care during the acute phase of the disease as its enhanced activity on the inflammed myocardium can precipitate serious arrhythmia (131). If myocarditis results in dilated cardiomyopathy and chronic heart failure, digoxin and an angiotensin-converting enzyme inhibitor are therapeutically useful (132). Even in non-complicated forms of myocarditis, when the course of the disease is benign, patients must undergo follow-up clinical and echocardiographic examinations and terminate any physical activity for at least 6 months following infection.

Novel molecular diagnostic methods of HPV in childhood. HPVs are small double-stranded DNA viruses that comprise a heterogeneous family, which consists of $>130$ different HPV types $(133,134)$. HPVs are associated with a wide range of cutaneous and mucosal infections in childhood, including common warts, genital warts, RRP, low-grade and high-grade squamous intraepithelial lesions (SILs), anal cancer, vaginal cancer and cervical cancer (134). Different HPV types have different biological, molecular and chemical properties (135). Based on their association with cervical cancer, HPV types are classified as 'high-risk' or 'low-risk' (136). In infancy and childhood, HPV infection involves skin warts, genital warts and juvenile RRP among both male and female neonates and children, as well as cervical SILs among adolescent girls. The recently introduced HPV vaccination is expected to limit 'high-risk' HPV-related infections; however, HPV infections will continue to affect children.

Several molecular assays are available for the detection of HPV infection in tissue and exfoliated cell samples and they present different sensitivities and specificities. These methods can be divided into the following assays: target amplification assays, including PCR and in situ PCR; direct hybridisation assays, such as Southern transfer hybridisation (STH), dot blot hybridisation (DBH) and in situ hybridisation (ISH); and signal amplified hybridisation assays, such as hybrid capture (HC) assays [reviewed by Mammas et al (137)]. HPV detection by PCR is the most widely used method and it can be performed either using type-specific primers or by consensus/general PCR primer pairs, such as the GP5+/6+ and MY09/11 primer pairs, or a combination of various non-degenerate primers containing inosine. The PCR amplicons can be either digested with restriction enzymes [restriction fragment length polymorphism (RFLP) analysis] and analysed by agarose gel electrophoresis, detected using a mixture of type-specific probes in an enzyme immunoassay, such as the HPVDNAChip and the APTIMA(R) HPV assay, or sequenced and compared to the GenBank sequences using BLAST (138). Novel real-time PCR methods, such as GenoID real-time PCR assay, Abbott's RealTime High Risk HPV assay, or the PreTect HPV-Proofer can provide high-throughput results $(139,140)$. The low sensitivity of STH and ISH assay can now be overcome with the INFORM HPV 3 and HPV-CARD assays, which show improved sensitivity $(141,142)$. HC 2 is the most reliable signal amplified hybridisation assay, with excellent sensitivity. Roche's Molecular Systems Amplicor HPV MWP assay and the CLART HPV 2 system also exhibit increased sensitivity and specificity (143).

A brief historical overview on the anti-vaccination movement. The opposition against vaccinations has its origin in the 19th century (144). Even before Edward Jenner's work, arguments against inoculation were set mostly by theologists, such as Reverend Edward Massey in 1722, who preached that diseases were sent by God to punish sin and that any attempt to prevent smallpox via inoculation was a 'diabolical operation' (144). The first Vaccination Act in England was passed in 1840. It introduced vaccination with vaccines developed from cow pox or vaccinia virus, but outlawed variolation, which had preceded vaccination, due to its greater risks (145). Thirteen years later, the 1853 Act enacted vaccination of all children at birth and added that parents or guardians, who failed to comply, would be strictly punished and even prosecuted (144,145). In 1867, the law extended the requirement to 14 years of age and its opponents argued upon individual freedom, which led eventually to a new law in 1898, that allowed for conscientious objection to compulsory vaccination. Vaccination practice in mid-19th century (arm-to-arm vaccination) carried substantial risks and the instruments used could contribute to severe adverse reactions (146). Alfred Russel Wallace (1823-1913), an explorer and co-discoverer of the principle of natural selection, along 
with other spiritualists, such as William Tebb (1830-1917) a radical liberal, founded the London Society for the Abolition of Compulsory Vaccination. Wallace had received vaccinations as a young man and all his 3 children were also vaccinated as well; however, it was the mandatory characteristic of the Act that motivated his social reformism. Although he was convinced that smallpox was a contagious disease, he also believed in a holistic view of health; thus, he claimed that differences in susceptibility could be caused by nutritional or sanitary deficiencies that contribute to the epidemiology of the diseases. Along with Tebb, they argued that liberty and science need to be taken into account; nevertheless liberty is far more important (145). However, at that time, Medicine and Pharmacology were in a pre-scientific level and hygiene was quite absent as well.

Immunisation in our days has proven to be one of the most important and cost-effective interventions in Public Health (147). Diseases, such as smallpox belong to history and vaccinated children protected against polio, measles, meningitis and other serious and sometimes fatal conditions (148). Thus, most parents and children have not experienced many of the vaccine-preventable diseases. Moreover, by not being well informed about the risks and sequelae of these conditions $(149,150)$, they are vulnerable to statements that lack scientific evidence, as it was with Andrew Wakefield's theory that linked vaccination against measles mumps and rubella (MMR) with autism in 1998. Wakefield's theory was deemed responsible for the decrease in immunisation rates in the UK from $92 \%$ to below $80 \%$ after the publication of his study (144).

Anti-vaccination arguments in the 21st century are often similar to those of 19th century, although they are spread mostly through the internet, where inaccurate data through blogs and fora increase vaccine rejection (147). Mainstream Medicine is questioned as well, and the use of complementary and alternative Medicine becomes increasingly popular (151). Some of the complementary and alternative therapies, such as homeopathy and chiropractice, are opposed to immunisations $(152,153)$. Constantine Hering (1800-1880), who is the 'father of American homeopathy', was the first homeopath, who declared his opposition to vaccination, which he termed 'poisoning'. A great deal of time must be dedicated by paediatricians and health organisations, in conjunction with government agencies such as CDC, to communicate effectively with parents and reliably inform them about the overall safety and efficacy of the vaccines. Web projects are increasingly being created by responsible and scientifically appropriate individuals, in order to counteract the misinformation on the web regarding vaccinations, through a series of information tools, such as scientific articles, educational information, video and multimedia presentations (147). Evidence-based proof, honest interest for an in depth dialogue through modern and everyday means of communication, such as social media and internet in general, is probably the best way to overcome vaccinophobia.

The educational challenge of Paediatric Virology. Paediatric Virology has been recently proposed as a new subspecialty candidate of Paediatrics (1). According to this proposal, Paediatric Virology trainees should gain valuable both clinical and research experience in the prevention and treatment of viral infections in neonates and children. It has been suggested that their training should be based on involvement in the clinical assessment, care and therapeutic management of hospitalised neonates and children with uncommon, recurrent, severe or complex viral infections. After their qualification, Paediatric Virology subspecialists are expected to play a multi-task role, not only in the university-based research and educational settings, but also in primary, secondary and tertiary services and the community (154).

Since the '1st Workshop on Paediatric Virology', held in Athens, Greece, on Saturday the 10th of October, 2015, Paediatric Virology has attracted the critical interest of several worldwide experts in the scientific fields of Neonatology, Paediatrics, Clinical Virology and PID (3). These experts have enthusiastically offered their valuable input to the debate of the potential strategically principal role of Paediatric Virology subspecialtists into clinical practice. This debate has already identified well defined challenges, difficulties and limitations to the role of Paediatric Virology as a separate subspecialty $(154,155)$. However, the potential value of Paediatric Virology training has undoubtedly been accepted and its official recognition remains to be further evaluated by the key worldwide scientific and academic stakeholders of Neonatology, Paediatrics, PID and Clinical Virology.

\section{Acknowledgements}

The authors would like to thank the chair persons, speakers and moderators of the '2nd Workshop on Paediatric Virology' for their continued support in providing the most up-to-date information. The authors would also like to thank the participants, who attended the workshop and provided feedback so that further work on improving the program can be achieved for the future. Last but not the least, this workshop would not have been possible without the dedicated hard work and strong commitment from the Congress Secretary Carol Kalogridis, the members of the PVSG and the whole organising team of the '21st World Congress on Advances in Oncology' and the '19th International Symposium on Molecular Medicine' for developing the scientific program, organising, coordinating and guaranteeing the success of this scientific event.

\section{References}

1. Mammas IN, Greenough A, Theodoridou M and Spandidos DA: Paediatric Virology: A new paediatric subspecialty? A proposal at the Workshop on Paediatric Virology, Athens, October 10, 2015. Exp Ther Med 11: 3-5, 2016.

2. Mammas IN, Greenough A, Theodoridou M, Kramvis A, Christaki I, Koutsaftiki C, Koutsaki M, Portaliou DM, Kostagianni G, Panagopoulou P, et al: Current views and advances on Paediatric Virology: An update for paediatric trainees. Exp Ther Med 11: 6-14, 2016.

3. Mammas IN and Spandidos DA: The subspecialty of Paediatric Virology: A 'mosaic tile' in future Paediatrics. Exp Ther Med 12: 539-540, 2016.

4. Mammas IN and Spandidos DA: Paediatric Virology in the Hippocratic Corpus. Exp Ther Med 12: 541-549, 2016.

5. 21 st World Congress on Advances in Oncology and 19th International Symposium on Molecular Medicine, October 6-8, 2016, Metropolitan Hotel, Athens, Greece. http://www.spandidos-publications.com.

6. Theodoridou M: The Greek experience of HIV-1 infection in children. Int J Mol Med 38: S64, 2016. 
7. Jones P: HIV infection and haemophilia. Arch Dis Child 66 364-368, 1991.

8. Politis C, Roumeliotou A, Germenis A and Papaevangelou G: Risk of acquired immune deficiency syndrome in multi transfused patients with thalassemia major. Plasma Ther Transfus Technol 7: 41-43, 1986

9. Connor EM1, Sperling RS, Gelber R, Kiselev P, Scott G, O'Sullivan MJ, VanDyke R, Bey M, Shearer W, Jacobson RL, et al: Reduction of maternal-infant transmission of human immunodeficiency virus type 1 with zidovudine treatment. Pediatric AIDS Clinical Trials Group Protocol 076 Study Group. N Engl J Med 331: 1173-1180, 1994.

10. Papagrigoriou-Theodoridou M: Pediatric AIDS. Pediatriki 60: 173-176, 1997.

11. Hellenic Center for Disease Control and Prevention (HCDCP): Recent data on HIV infection in Greece, October 2014 http://www2.keelpno.gr/blog/?p=6240\&lang=en. Accessed April 8, 2015.

12. Siberry GK: Preventing and managing HIV infection in infants, children, and adolescents in the United States. Pediatr Rev 35 268-286, 2014

13. Spoulou V, Kanaka-Gantenbein C, Bathrellou I, Mora S, Mostrou G, Sidossis L, Chrousos G and Theodoridou M: Monitoring of lipodystrophic and metabolic abnormalities in HIV-1 infected children on antiretroviral therapy. Hormones (Athens) 10: 149-155, 2011.

14. Sohn AH and Hazra R: The changing epidemiology of the global paediatric HIV epidemic: Keeping track of perinatally HIV-infected adolescents. J Int AIDS Soc 16: 18555, 2013.

15. Luzuriaga $\mathrm{K}$ and Mofenson LM: Challenges in the elimination of Pediatric HIV-1 infection. N Engl J Med 374: 761-770, 2016.

16. Kramvis A: Hepatitis B vaccination in Africa: Current situation and future challenges. Int J Mol Med 38: S64, 2016.

17. World Health Organization: Hepatitis B. Fact sheet No. 204 Updated July 2016. http://www.who.int/mediacentre/factsheets/fs204/en/.

18. Kramvis A and Kew MC: Epidemiology of hepatitis B virus in Africa, its genotypes and clinical associations of genotypes. Hepatol Res 37 (s1): S9-S19, 2007.

19. Parkin DM, Sitas F, Chirenje M, Stein L, Abratt R and Wabinga H Part I: Cancer in Indigenous Africans - burden, distribution, and trends. Lancet Oncol 9: 683-692, 2008.

20. World Health Organization: Glasgow Declaration on Hepatitis, 2015. http://www.who.int/hepatitis/glasgow-declaration-on-vira l-hepatitis/en/.

21. World Health Organization: HIV and hepatitis coinfections, 2015. http://www.who.int/hiv/topics/hepatitis/en/.

22. Francois G, Dochez C, Mphahlele MJ, Burnett RJ, Van Hal G and Meheus A: Hepatitis B vaccination in Africa: Mission accomplished? South Afr J Epidemiol Infect 23: 24-28, 2008.

23. World Health Organization: WHO/UNICEF estimates of national immunization coverage. Updated July 2016. http:// www.who.int/immunization/monitoring_surveillance/routine/ coverage/en/index4.html.

24. Kramvis A: Treatment options for Hepatitis $\mathrm{C}$ virus in childhood. Int J Mol Med 38: S66, 2016

25. World Health Organization: Hepatitis C. Fact sheet NO. 164 , Updated July 2016. http://www.who.int/mediacentre/factsheets/fs164/en/.

26. Pawlowska M, Domagalski K, Pniewska A, Smok B, Halota W and Tretyn A: What's new in hepatitis $C$ virus infections in children? World J Gastroenterol 21: 10783-10789, 2015.

27. Abd-Elgawad MM, Baddour NM and Salem MAE: Chronic hepatitis C in children: Clinical spectrum and histopathological study. Alexandria Med J 49: 363-368, 2013.

28. Cottrell EB, Chou R, Wasson N, Rahman B and Guise JM: Reducing risk for mother-to-infant transmission of hepatitis $\mathrm{C}$ virus: A systematic review for the U.S. Preventive Services Task Force. Ann Intern Med 158: 109-113, 2013.

29. Druyts E, Thorlund K, Wu P, Kanters S, Yaya S, Cooper CL and Mills EJ: Efficacy and safety of pegylated interferon alfa-2a or alfa- $2 b$ plus ribavirin for the treatment of chronic hepatitis $C$ in children and adolescents: A systematic review and meta-analysis. Clin Infect Dis 56: 961-967, 2013.

30. Wirth S, Ribes-Koninckx C, Calzado MA, Bortolotti F, Zancan L, Jara P, Shelton M, Kerkar N, Galoppo M, Pedreira A, et al: High sustained virologic response rates in children with chronic hepatitis $\mathrm{C}$ receiving peginterferon alfa- $2 \mathrm{~b}$ plus ribavirin. J Hepatol 52: 501-507, 2010.
31. Pawłowska M, Pilarczyk M and Halota W: Virologic response to treatment with Pegylated Interferon alfa-2b and Ribavirin for chronic hepatitis C in children. Med Sci Monit 16: CR616-CR621, 2010.

32. World Health Organization: Guidelines for the screening, care and treatment of persons with chronic hepatitis $\mathrm{C}$ infection. Updated April 2016. http://www.who.int/hepatitis/publications/ hepatitis-c-guidelines-2016/en/.

33. Ohmer $\mathrm{S}$ and Honegger J: New prospects for the treatment and prevention of hepatitis $\mathrm{C}$ in children. Curr Opin Pediatr 28: 93-100, 2016

34. Thiagarajan P: Zika Virus in pregnancy and infancy - What do the paediatricians need to know? Int J Mol Med 38: S64, 2016.

35. Centers for Disease Control and Prevention: Zika virus and complications: Questions and answers. Updated November 15, 2016. http://www.who.int/features/qa/zika/en/.

36. Centers for Disease Control and Prevention: Zika Virus - what clinicians need to know? 2016. http://emergency.cdc. gov/coca/ppt/2016/01_26_16_zika.pdf.

37. Jamieson D: 10 Questions About Zika: The CDC Answers February 17, 2016. http://www.medscape.com/viewarticle/859014.

38. CentersforDiseaseControl andPrevention:Zikatravelinformation 2016. http://wwwnc.cdc.gov/travel/page/zika-travel-information.

39. Centers for Disease Control and Prevention: Zika Virus: Symptoms, diagnosis, \& treatment, 2016. http://www.cdc. gov/zika/symptoms/index.html.

40. Basarab M, Bowman C, Aarons EJ and Cropley I: Zika virus. BMJ 352: i1049, 2016.

41. Russell K, Oliver SE, Lewis L, Barfield WD, Cragan J, Meaney-Delman D, Staples JE, Fischer M, Peacock G, Oduyebo T, et al; Contributors: Update: Interim Guidance for the Evaluation and Management of Infants with Possible Congenital Zika Virus Infection - United States, August 2016. MMWR Morb Mortal Wkly Rep 65: 870-878, 2016.

42. Gardner S: It's never just a virus - experiences from the frontline. Int J Mol Med 38: S65, 2016.

43. Cleveland Clinic: Recurrent Fever - When It's a Virus. When It's Something More, 2016. http://my.clevelandclinic.org/health/transcripts/1578_recurrent-fever-when-it-s-a-virus-when-it-s-som ething-more.

44. Chad Hayes: 'Just a Virus': What Your Doctor Meant to Say, 2016. http://www.chadhayesmd.com/just-a-virus-what-your-doc tor-meant-to-say/.

45. Chad Hayes S: Your kid is really sick, but the doctor says it's 'just a virus'. The Washington Post, March 17, 2015. https:// www.washingtonpost.com/national/health-science/your-kid-i s-really-sick-but-the-doc-says-its-just-a-virus/2015/03/16/e $89 \mathrm{f}$ f86a-c347-11e4-ad5c-3b8ce89f1b89_story.html?utm_term=. a7a5bf $82 b 12 d$

46. Quora: Why do doctors prescribe antibiotics for viruses/viral infections? 2016. https://www.quora.com/Why-do-doctors-pres cribe-antibiotics-for-viruses-viral-infections.

47. Craig JC, Williams GJ, Jones M, Codarini M, Macaskill P, Hayen A, Irwig L, Fitzgerald DA, Isaacs D and McCaskill M: The accuracy of clinical symptoms and signs for the diagnosis of serious bacterial infection in young febrile children: Prospective cohort study of 15781 febrile illnesses. BMJ 340: c1594, 2010.

48. Campaign SS: Guidelines, Society of Critical Care Medicine, 2016. http://www.survivingsepsis.org/guidelines/Pages/default.aspx.

49. Condliffe J: New Study Reveals Just How Sick Families With Kids Get. Gizmodo, July 8, 2015. http://gizmodo.com/new-studyreveals-just-how-sick-families-with-kids-get-1722654292.

50. Stiehm ER: Approach to the child with recurrent infections. UpToDate, 2016. http://www.uptodate.com/contents/approach-to -the-child-with-recurrent-infections.

51. Bryant K: It's not just a virus. http://itsnotjustavirus.com.

52. Papaioannou G: Multimodality imaging of viral infections in children: CNS and beyond. Int J Mol Med 38: S65, 2016.

53. Lo CP and Chen CY: Neuroimaging of viral infections in infants and young children. Neuroimaging Clin N Am 18: 119-132, viii, 2008.

54. Shaw DWW and Cohen WA: Viral infections of the CNS in children: Imaging features. AJR Am J Roentgenol 160: 125-133, 1993.

55. Gupta K, Banerjee A, Saggar K, Ahluwalia A and Saggar K: A prospective study of magnetic resonance imaging patterns of central nervous system infections in pediatric age group and young adults and their clinico-biochemical correlation. J Pediatr Neurosci 11: 46-51, 2016. 
56. Askalan R, Laughlin S, Mayank S, Chan A, MacGregor D, Andrew M, Curtis R, Meaney B, deVeber G and Hunter JV: Chickenpox and stroke in childhood: A study of frequency and causation. Stroke 32: 1257-1262, 2001.

57. Koelman DL, Chahin S, Mar SS, Venkatesan A, Hoganson GM, Yeshokumar AK, Barreras P, Majmudar B, Klein JP, Chitnis T, et al: Acute disseminated encephalomyelitis in 228 patients: A retrospective, multicenter US study. Neurology 86 : 2085-2093, 2016.

58. Esposito S, Di Pietro GM, Madini B, Mastrolia MV and Rigante D: A spectrum of inflammation and demyelination in acute disseminated encephalomyelitis (ADEM) of children. Autoimmun Rev 14: 923-929, 2015.

59. Guo W, Wang J, Sheng M, Zhou M and Fang L: Radiological findings in 210 paediatric patients with viral pneumonia: A retrospective case study. Br J Radiol 85: 1385-1389, 2012.

60. Virkki R, Juven T, Rikalainen H, Svedström E, Mertsola J and Ruuskanen O: Differentiation of bacterial and viral pneumonia in children. Thorax 57: 438-441, 2002.

61. Bass D, Cordoba E, Dekker C, Schuind A and Cassady C: Intestinal imaging of children with acute rotavirus gastroenteritis. J Pediatr Gastroenterol Nutr 39: 270-274, 2004.

62. Fretzayas A, Moustaki M, Attilakos A, Brozou T and Nicolaidou P: Acalculous cholecystitis or biliary dyskinesia for Epstein-Barr virus gallbladder involvement? Prague Med Rep 115: 67-72, 2014

63. Meier JD and Grimmer JF: Evaluation and management of neck masses in children. Am Fam Physician 89: 353-358, 2014.

64. Stenner M and Rudack C: Diseases of the nose and paranasal sinuses in child. GMS Curr Top Otorhinolaryngol Head Neck Surg 13: Doc10, 2014

65. Long $\mathrm{G}$ and Gibbon WW: Ultrasonography in the diagnosis of chickenpox-related osteomyelitis. J Ultrasound Med 17: 29-32, 1998.

66. Melidou A: Influenza in childhood: A usual suspect. Int J Mol Med 38: S66, 2016.

67. Christoforidi M, Melidou A, Gioula G, Exindari M and Malisiovas N: Influenza virus activity in children $<18$ years old in N. Greece, 2015-2016. Int J Mol Med 38: S68, 2016.

68. Lafond KE, Nair H, Rasooly MH, Valente F, Booy R, Rahman M, Kitsutani P, Yu H, Guzman G, Coulibaly D, et al; Global Respiratory Hospitalizations-Influenza Proportion Positive (GRIPP) Working Group: Global Role and Burden of Influenza in Pediatric Respiratory Hospitalizations, 1982-2012: A Systematic Analysis. PLoS Med 13: e1001977, 2016.

69. Bennet R, Hamrin J, Wirgart BZ, Östlund MR, Örtqvist A and Eriksson M: Influenza epidemiology among hospitalized children in Stockholm, Sweden 1998-2014. Vaccine 34: 3298-3302, 2016.

70. World Health Organization: Risk Assessment - Seasonal Influenza A(H1N1)pdm09. February 8, 2016. http://www.who.int/ influenza/publications/riskassessment_AH1N1pdm09_201602/ en/.

71. Hellenic Center for Disease Control and Prevention: Annual report on epidemiological surveillance of influenza during the period 2015-2016. http://www.keelpno.gr.

72. Hurt AC, Besselaar TG, Daniels RS, Ermetal B, Fry A, Gubareva L, Huang W, Lackenby A, Lee RT, Lo J, et al: Global update on the susceptibility of human influenza viruses to neuraminidase inhibitors, 2014-2015. Antiviral Res 132: 178-185, 2016.

73. Kissling E and Valenciano M: Early influenza vaccine effectiveness results 2015-16: I-MOVE multicentre case-control study. Euro Surveill 21: pii30134, 2016.

74. Centers for Disease Control and Prevention: ACIP votes down use of LAIV for 2016-2017 flu season. June 22, 2016. http://www. cdc.gov/media/releases/2016/s0622-laiv-flu.html.

75. Pebody R, Warburton F, Ellis J, Andrews N, Potts A, Cottrell S, Johnston J, Reynolds A, Gunson R, Thompson C, et al: Effectiveness of seasonal influenza vaccine in preventing laboratory-confirmed influenza in primary care in the United Kingdom: 2015/16 mid-season results. Euro Surveill 21: pii30179, 2016.

76. NohynekHandTHLInfluenzaResearchTeam:Seasonalchildhood influenza vaccinations - experiences from Finland. April 4, 2016. http://www.nvm2016.is/sites/default/files/Nohynek_NorVac_ influenzaLessonsNohynek_short.pdf.

77. Koutsaki M and Dinopoulos A: Neurologic manifestations of Influenza A infection (H1N1 pandemic strain) in Paediatrics. Int J Mol Med 38: S66, 2016.
78. Barker WH and Mullooly JP: Impact of epidemic type A influenza in a defined adult population. Am J Epidemiol 112: $798-811,1980$

79. Glezen WP: Serious morbidity and mortality associated with influenza epidemics. Epidemiol Rev 4: 25-44, 1982.

80. Jelliffe S: Nervous and mental disturbances of Influenza. N Y Med J 108: 807-811, 1918.

81. Oxford JS: Influenza A pandemics of the 20th century with special reference to 1918: Virology, pathology and epidemiology. Rev Med Virol 10: 119-133, 2000.

82. Ekstrand JJ: Neurologic complications of influenza. Semin Pediatr Neurol 19: 96-100, 2012

83. Muhammad Ismail HI, Teh CM and Lee YL; National Paediatric H1N1 Study Group: Neurologic manifestations and complications of pandemic influenza A H1N1 in Malaysian children: What have we learnt from the ordeal? Brain Dev 37: 120-129, 2015.

84. Bakken IJ, Aaberg KM, Ghaderi S, Gunnes N, Trogstad L, Magnus $P$ and Håberg SE: Febrile seizures after 2009 influenza A (H1N1) vaccination and infection: A nationwide registry-based study. BMC Infect Dis 15: 506, 2015.

85. Baltagi SA, Shoykhet M, Felmet K, Kochanek PM and Bell MJ: Neurological sequelae of 2009 influenza A (H1N1) in children: A case series observed during a pandemic. Pediatr Crit Care Med11: 179-184, 2010.

86. Sachedina N and Donaldson LJ: Paediatric mortality related to pandemic influenza A H1N1 infection in England: An observational population-based study. Lancet 376: 1846-1852, 2010.

87.Kwong KL, Lam SY, Que TL and Wong SN: Influenza A and febrile seizures in childhood. Pediatr Neurol 35: 395-399, 2006.

88.Amin R, Ford-Jones E, Richardson SE, MacGregor D, Tellier R, Heurter H, Fearon M and Bitnun A: Acute childhood encephalitis and encephalopathy associated with influenza: A prospective 11-year review. Pediatr Infect Dis J 27: 390-395, 2008

89. Newland JG, Laurich VM, Rosenquist AW, Heydon K, Licht DJ, Keren R, Zaoutis TE, Watson B, Hodinka RL and Coffin SE: Neurologic complications in children hospitalized with influenza: Characteristics, incidence, and risk factors. J Pediatr 150: 306-310, 2007.

90. Ekstrand JJ, Herbener A, Rawlings J, Turney B, Ampofo K, Korgenski EK and Bonkowsky JL: Heightened neurologic complications in children with pandemic H1N1 influenza. Ann Neurol 68: 762-766, 2010.

91. Ozkan M, Tuygun N, Erkek N, Aksoy A and Yildiz YT: Neurologic manifestations of novel influenza A (H1N1) virus infection in childhood. Pediatr Neurol 45: 72-76, 2011.

92. Straussberg R, Amir J, Harel L, Punsky I and Bessler H: Pro- and anti-inflammatory cytokines in children with febrile convulsions. Pediatr Neurol 24: 49-53, 2001.

93. Hall CB, Long CE, Schnabel KC, Caserta MT, McIntyre KM, Costanzo MA, Knott A, Dewhurst S, Insel RA and Epstein LG: Human herpesvirus-6 infection in children: a prospective study of complications and reactivation. N Engl J Med 331: 432-438, 1994.

94. Kostagianni G: Otolaryngologist's surgical approaches of complicated paediatric viral infections. Int J Mol Med 38: S65, 2016.

95. Mammas IN, Sourvinos G and Spandidos DA: Human papilloma virus (HPV) infection in children and adolescents. Eur J Pediatr 168: 267-273, 2009.

96. Lipke MM: An armamentarium of wart treatments. Clin Med Res 4: 273-293, 2006

97. Misir AF, Demiriz L and Barut F: Laser treatment of an oral squamous papilloma in a pediatric patient: A case report. J Indian Soc Pedod Prev Dent 31: 279-281, 2013.

98. Rush J and Dinulos JG: Childhood skin and soft tissue infections: New discoveries and guidelines regarding the management of bacterial soft tissue infections, molluscum contagiosum, and warts. Curr Opin Pediatr 28: 250-257, 2016.

99. Chauhan N, Robinson JL, Guillemaud J and El-Hakim H: Acute herpes simplex laryngotracheitis: Report of two pediatric cases and review of the literature. Int J Pediatr Otorhinolaryngol 71: 341-345, 2007

100. Greenough A, Drysdale S, Broughton S and Bont L: The impact of viral infections on the long-term outcomes of prematurely born infants. Int J Mol Med 36: S89, 2015 
101. Woods CR, Cash ED, Smith AM, Smith MJ, Myers JA, Espinosa $\mathrm{CM}$ and Chandran SK: Retropharyngeal and parapharyngeal abscesses among children and adolescents in the United States: Epidemiology and management trends, 2003-2012. J Pediatric Infect Dis Soc 5: 259-268, 2016.

102. Achtsidis V and Kozanidou E: Paediatric viral conjunctivitis Diagnosis and treatment. Int J Mol Med 38: S66, 2016.

103. American Academy of Ophthalmology: 2016-2017 Basic and Clinical Science Course, Section 6: Paediatric Ophthalmology and strabismus. 2016

104. Azari AA and Barney NP: Conjunctivitis: a systematic review of diagnosis and treatment. JAMA 310: 1721-1729, 2013.

105. Visscher KL, Hutnik CM and Thomas M: Evidence-based treatment of acute infective conjunctivitis: Breaking the cycle of antibiotic prescribing. Can Fam Physician 55: 1071-1075, 2009.

106. Everitt HA, Little PS and Smith PW: A randomised controlled trial of management strategies for acute infective conjunctivitis in general practice. BMJ 333: 321, 2006.

107. Kanski JJ: Clinical Ophthalmology: a systematic approach 6th edition. Butterworth-Heinemann/Elsevier, New York, NY, 2007.

108. Buznach N, Dagan R and Greenberg D: Clinical and bacterial characteristics of acute bacterial conjunctivitis in children in the antibiotic resistance era. Pediatr Infect Dis J 24: 823-828, 2005.

109. Rose PW, Harnden A, Brueggemann AB, Perera R, Sheikh A, Crook D and Mant D: Chloramphenicol treatment for acute infective conjunctivitis in children in primary care: A randomised double-blind placebo-controlled trial. Lancet 366 : $37-43,2005$

110. Koutsaftiki C: Coxsackie virus A6 and onychomadesis: A case report and literature review. Int J Mol Med 38: S67, 2016.

111. Clementz GC and Mancini AJ: Nail matrix arrest following hand-foot-mouth disease: A report of five children. Pediatr Dermatol 17: 7-11, 2000.

112. Bernier V, Labrèze C, Bury $F$ and Taïeb A: Nail matrix arrest in the course of hand, foot and mouth disease. Eur J Pediatr 160: 649-651, 2001.

113. Solomon T, Lewthwaite P, Perera D, Cardosa MJ, McMinn P and Ooi MH: Virology, epidemiology, pathogenesis, and control of enterovirus 71. Lancet Infect Dis 10: 778-790, 2010.

114. Gao LD, Hu SX, Zhang H, Luo KW, Liu YZ, Xu QH, Huang W, Deng ZH, Zhou SF, Liu FQ, et al: Correlation analysis of EV71 detection and case severity in hand, foot, and mouth disease in the Hunan Province of China. PLoS One 9: e100003, 2014.

115. Osterback R, Vuorinen T, Linna M, Susi P, Hyypiä T and Waris M: Coxsackievirus A6 and hand, foot, and mouth disease, Finland. Emerg Infect Dis 15: 1485-1488, 2009.

116. Sinclair C, Gaunt E, Simmonds P, Broomfield D, Nwafor N, Wellington L, Templeton K, Willocks L, Schofield $\mathrm{O}$ and Harvala H: Atypical hand, foot, and mouth disease associated with coxsackievirus A6 infection, Edinburgh, United Kingdom, January to February 2014. Euro Surveill 19: 20745, 2014.

117. Fujimoto T, Iizuka S, Enomoto M, Abe K, Yamashita K, Hanaoka N, Okabe N, Yoshida H, Yasui Y, Kobayashi M, et al: Hand, foot, and mouth disease caused by coxsackievirus A6, Japan, 2011. Emerg Infect Dis 18: 337-339, 2012.

118. Huang WC, Huang LM, Lu CY, Cheng AL and Chang LY: Atypical hand-foot-mouth disease in children: A hospital-based prospective cohort study. Virol J 10: 209, 2013.

119. Kaminska K, Martinetti G, Lucchini R, Kaya G and Mainetti C: Coxsackievirus A6 and hand, foot and mouth disease: Three case reports of familial child-to-immunocompetent adult transmission and a literature review. Case Rep Dermatol 5: 203-209, 2013.

120. Miller GD and Tindall JP: Hand-foot-and-mouth disease. JAMA 203: 827-830, 1968.

121. Jiang M, Wei D, Ou WL, Li KX, Luo DZ, Li YQ, Chen E and Nong GM: Autopsy findings in children with hand, foot, and mouth disease. N Engl J Med 367: 91-92, 2012.

122. Calachanis M: Coxsackie viruses and myocarditis in children. Int J Mol Med 38: S66, 2016.

123. Dery P, Marks MI and Shapera R: Clinical manifestations of coxsackievirus infections in children. Am J Dis Child 128: 464-468, 1974.

124. Hosier DM and Newton WA Jr: Serious Coxsackie infection in infants and children; myocarditis, meningoencephalitis, and hepatitis. AMA J Dis Child 96: 251-267, 1958.

125. Friedman RA, Schowengerdt KO Jr and Towbin JA: Myocarditis. In: The Science and Practice of Pediatric Cardiology. 2nd edition. Garson A Jr, Bricker JT, Fisher DJ and Neish SR (eds). Williams \& Wilkins, Baltimore, MD, pp1777-1794, 1998.
126. Cherry JD, Jahn CL and Meyer TC: Paroxysmal atrial tachycardia associated with ECHO 9 virus infection. Am Heart J 73: 681-686, 1967.

127. Huang M, Bigos D and Levine M: Ventricular arrhythmia associated with respiratory syncytial viral infection. Pediatr Cardiol 19: 498-500, 1998.

128. Balaji S, Wiles HB, Sens MA and Gillette PC: Immunosuppressive treatment for myocarditis and borderline myocarditis in children with ventricular ectopic rhythm. Br Heart J 72: 354-359, 1994.

129. Friedman RA, Kearney DL, Moak JP, Fenrich AL and Perry JC: Persistence of ventricular arrhythmia after resolution of occult myocarditis in children and young adults. J Am Coll Cardiol 24 780-783, 1994

130. Schieken RM and Myers MG: Complete heart block in viral myocarditis. J Pediatr 87: 831-832, 1975.

131. Matsumori A, Igata H, Ono K, Iwasaki A, Miyamoto T, Nishio R and Sasayama S: High doses of digitalis increase the myocardial production of proinflammatory cytokines and worsen myocardial injury in viral myocarditis: A possible mechanism of digitalis toxicity. Jpn Circ J 63: 934-940, 1999.

132. Lewis $A B$ and Chabot $M$ : The effect of treatment with angiotensin-converting enzyme inhibitors on survival of pediatric patients with dilated cardiomyopathy. Pediatr Cardiol 14: 9-12, 1993.

133.Zaravinos A and Mammas IN: Sourvinos and Spandidos DA Molecular detection of human papillomaviruses in childhood: An update. Int J Mol Med 38: S68, 2016.

134. zur Hausen H: Papillomaviruses and cancer: From basic studies to clinical application. Nat Rev Cancer 2: 342-350, 2002.

135. Mammas IN, Spandidos DA and Sourvinos G: Genomic diversity of human papillomaviruses (HPV) and clinical implications: An overview in adulthood and childhood. Infect Genet Evol 21: 220-226, 2014

136.Peto J, Gilham C, Deacon J, Taylor C, Evans C, Binns W, Haywood M, Elanko N, Coleman D, Yule R, et al: Cervical HPV infection and neoplasia in a large population-based prospective study: The Manchester cohort. Br J Cancer 91: 942-953, 2004.

137. Mammas IN, Zaravinos A, Sourvinos G and Spandidos DA: Detection of human papillomavirus in bronchoalveolar lavage samples in immunocompetent children. Pediatr Infect Dis J 30: 384-386, 2011

138. Arens M: Clinically relevant sequence-based genotyping of HBV, HCV, CMV, and HIV. J Clin Virol 22: 11-29, 2001.

139. Takács T, Jeney C, Kovács L, Mózes J, Benczik M and Sebe A Molecular beacon-based real-time PCR method for detection of 15 high-risk and 5 low-risk HPV types. J Virol Methods 149: $153-162,2008$

140. de Araujo MR, De Marco L, Santos CF, Rubira-Bullen IR, Ronco G, Pennini I, Vizzini L, Merletti F and Gillio-Tos A GP5+/6+ SYBR Green methodology for simultaneous screening and quantification of human papillomavirus. J Clin Virol 45: 90-95, 2009.

141. Guo M, Gong Y, Deavers M, Silva EG, Jan YJ, Cogdell DE, Luthra R, Lin E, Lai HC, Zhang W, et al: Evaluation of a commercialized in situ hybridization assay for detecting human papillomavirus DNA in tissue specimens from patients with cervical intraepithelial neoplasia and cervical carcinoma. J Clin Microbiol 46: 274-280, 2008.

142. Algeciras-Schimnich A, Policht F, Sitailo S, Song M, Morrison L and Sokolova I: Evaluation of quantity and staining pattern of human papillomavirus (HPV)-infected epithelial cells in thin-layer cervical specimens using optimized HPV-CARD assay. Cancer 111: 330-338, 2007.

143. Hesselink AT, van den Brule AJ, Brink AA, Berkhof J, van Kemenade FJ, Verheijen RH and Snijders PJ: Comparison of hybrid capture 2 with in situ hybridization for the detection of high-risk human papillomavirus in liquid-based cervical samples. Cancer 102: 11-18, 2004.

144. Koutsaftiki C: The antivaccination movement: A brief historical overview. Int J Mol Med 38: S67, 2016.

145. Weber TP: Alfred Russel Wallace and the antivaccination movement in Victorian England. Emerg Infect Dis 16: 664-668, 2010.

146. Baxby D: Smallpox vaccination techniques; from knives and forks to needles and pins. Vaccine 20: 2140-2149, 2002.

147. Ferro A, Bonanni P, Castiglia P, Montante A, Colucci M, Miotto S, Siddu A, Murrone L and Baldo V: Improving vaccination social marketing by monitoring the web. Ann Ig 26 (3 Suppl 1): 54-64, 2014 (In Italian) 
148. Peltola H,Heinonen OP, Valle M,Paunio M, Virtanen M, Karanko $\mathrm{V}$ and Cantell K: The elimination of indigenous measles, mumps, and rubella from Finland by a 12-year, two-dose vaccination program. N Engl J Med 331: 1397-1402, 1994.

149. Guerin $\mathrm{N}$ and Roure C: Immunisation coverage in the European Union. Euro Surveill 2: 2-4, 1997.

150.Hammer LD, Curry ES, Harlor AD, Laughlin JJ, Leeds AJ, Lessin HR, Rodgers CT, Granado-Villar DC, Brown JM, Cotton WH, et al; Council on Community Pediatrics: Increasing immunization coverage. Pediatrics 125: 1295-1304, 2010.

151. Adams D, Dagenais S, Clifford T, Baydala L, King WJ, Hervas-Malo M, Moher D and Vohra S: Complementary and alternative medicine use by pediatric specialty outpatients. Pediatrics 131: 225-232, 2013
152. Schmidt K and Ernst E: MMR vaccination advice over the Internet. Vaccine 21: 1044-1047, 2003.

153. Lee AC and Kemper KJ: Homeopathy and naturopathy: Practice characteristics and pediatric care. Arch Pediatr Adolesc Med 154: 75-80, 2000.

154. Mammas IN, Theodoridou M, Sourvinos G and Spandidos DA The educational challenge of Paediatric Virology. Int J Mol Med 38: S65, 2016.

155. Mammas IN, Theodoridou M, Sourvinos G and Spandidos DA Paediatric Virology as new paediatric subspecialty: Challenges, difficulties and limitations. Int J Mol Med 38: S67, 2016. 